\section{UK ministry under fire over handling of BSE research}

\section{David Dickson, London}

Britain's Ministry of Agriculture, Fisheries and Food (MAFF) was accused this week of hindering research into bovine spongiform encephalopathy (BSE) — mad cow disease - during the 1980s.

Maitland Mackie, former chairman of the animals committee of the then Agricultural and Food Research Council, said that MAFF awarded BSE-research grants to scientific "novices" working in its own laboratories, rather than to those in independent institutions with long experience in related areas.

Mackie's comments came shortly before the publication this week of the conclusions of a public inquiry led by Lord Phillips into the BSE outbreak.

The inquiry is expected to distribute blame widely among MAFF officials and their political bosses for giving excessive weight to the interests of the food industry in their handling of information about the spread of BSE and its likely implications for human health.

The Phillips report is also expected to look critically at the impact of cuts to agricultural research in the 1980s, and the efforts by MAFF to exert control over the results that were published.

In evidence to the inquiry, for example, Alan Dickinson, head of the Neuropathogenesis Unit in Edinburgh between 1981 and 1987, had claimed that the overall research funds "were given disproportionately to those without previous experience", with the result that his own "chronically underfunded" unit had had its work "seriously hindered".

Speaking this week in a radio interview with the $B B C$, Mackie argued that MAFF's decision to channel funding to its own institutes had held up vital research into BSE by two years.

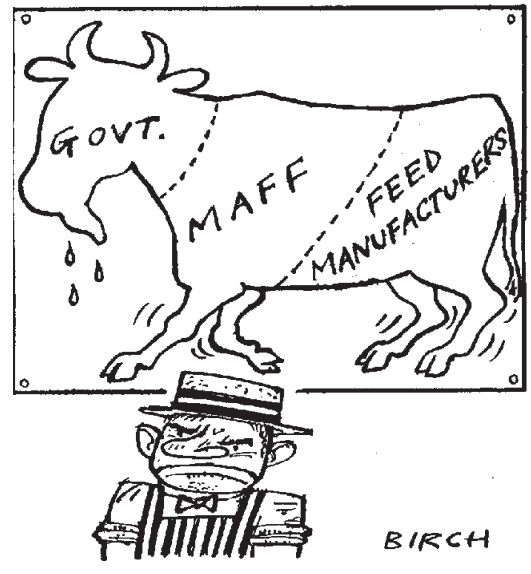

\title{
Global warming identified as main threat to coral reefs
}

Peter Pockley, Bali

A report released this week paints a bleak picture of the condition of the world's coral reefs. And it names global warming as the culprit behind much of the damage.

Only two years after a survey of the world's coral reefs found $11 \%$ had been destroyed before 1998, a more extensive assessment by 80 countries of their own reefs - most for the first time - has raised the total to $27 \%$ "effectively lost" by late 2000 .

The latest measurements come from the Global Coral Reef Monitoring Network, the operational unit of the International Coral Reef Initiative, and they take account of the massive bleaching of corals that took place in 1998. The network identified a further 14\% of reefs that are at "critical" risk of being lost within 2-10 years, and 18\% more as being "threatened" in 10-30 years.

The details were released this week at the ninth International Coral Reef Symposium in Bali, Indonesia, an island that sits at the centre of the archipelago harbouring the greatest diversity of coral species.

The coordinator of both surveys, Clive Wilkinson of the Australian Institute of Marine Science (AIMS), says the agenda up to 1998 had primarily been to curb human impacts on reefs. Damage is now documented from over-fishing for subsistence and export, from the live fish trade, from fishing by explosion and poisoning, as well as from sewage, and excessive sediments and nutrients running off urban and agricultural development.

Although these influences remain, the new report argues that the main problem has now become global climate change, to which corals are proving acutely sensitive. Terry Done, also of AIMS and president of the con-

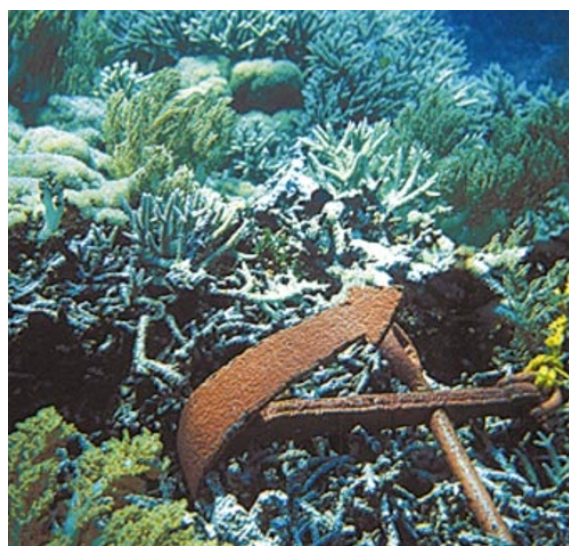

Damage done: bleached coral in Indonesia.

ference, joined Wilkinson in stressing the need to curb greenhouse gas emissions.

The problems are most severe in the wider Indian Ocean, where there has been $59 \%$ loss but "reasonable chances of recovery for remote reefs", according to the report. Next in order are reefs in the Middle East (35\% damage and "low chances for shortterm recovery"), and Southeast and East Asia (34\% loss "with reasonable chances for slow recovery on remote reefs").

The Caribbean/Atlantic reported a loss of $22 \%$, mostly from human impact - but with relatively fast recovery. In contrast, the extensive reefs in the Pacific and off Australia are reported as being "in reasonably good health with a positive outlook unless global climate change events like those of 1998 strike these areas".

Wilkinson says it is significant that countries are "no longer in a state of denial and are appealing for help", as exemplified by Indonesian officials at the conference. | http://coral.aoml.noaa.gov.gcrmn/gcrmn.html

\section{Carbon sequestration gains support}

Colin Macilwain, Washington

Princeton University has been awarded

\$15 million from the petrochemical company BP and $\$ 5$ million from the car maker Ford to set up a project to study carbon sequestration and other possible solutions to the problem of global climate change.

The project will try to find measures that will have limited environmental impact and which avoid "prohibitive economic costs" and "prohibitive disruptions in patterns of energy consumption". These are expected to include work on the value of carbon sequestration in underground geological formations and the

$\approx \odot 2000$ Macmillan Magazines Ltd possibility of switching to hydrogen fuels.

The research funding will be spread over ten years, under a Carbon Mitigation Initiative. The university describes it as the largest corporate grant in its history.

The initiative was due to be announced yesterday ( 25 October) in New York by BP chairman Sir John Browne and Harold Shapiro, president of Princeton.

Carbon sequestration has become a popular subject recently, despite doubts about its feasibility, as it has become apparent that the United States is not likely to act to reduce its carbon emissions. 